\title{
SIMULTANEOUS LOCALIZATION OF NEUROPEPTIDES (SUBSTANCE P AND VASOACTIVE INTESTINAL POLYPEPTIDE) WITH ACETYLCHOLINE- LIKE CATION AT ELECTRON MICROSCOPIC LEVEL
}

\author{
Philippe ANGlade ${ }^{1+}$ and Shigeru TSUJI ${ }^{2}$ \\ National Institute for Physiological Sciences ${ }^{1}$, Myodaiji, Okazaki 444 \\ and Départment de Cytologie ${ }^{2}$, Institut des Neurosciences, \\ Université P. et M. Curie, 7 Quai Saint-Bernard, \\ 75230 Paris CEDEX 05, France
}

Received for publication January 26, 1990 and in revised form February 23, 1990

\begin{abstract}
A method was devised for the simultaneous localization of neuropeptides and acetylcholine ( $\mathrm{ACh}$ )-like cation at ultrastructural level in a paraformaldehyde fixed nervous tissue (myenteric plexus). In order to minimize the loss of tissual $\mathbf{A C h}$, no membrane permeabilization was made before the immunocytochemical reaction. Conventional pre-embedding immunoperoxidase reaction for neuropeptides detection [substance $P$ and vasoactive intestinal polypeptide (VIP)] was followed by cytochemical ionic fixation of ACh-like cation. All the substance P-or VIP-immunoreactive nerve endings possessed punctiform precipitates of ACh-like cations situated in the small clear synaptic vesicles $(30-50 \mathrm{~nm})$. In the vicinity of substance $P$ - and VIP-immunoreactive nerve terminals, some other nerve terminals containing ACh-like cations did not contain any peptide immunoreactivity.
\end{abstract}

Cholinergic neurotransmission in the myenteric plexus is known to be modulated by neuropeptides. To date the precise mechanism of interaction between acetylcholine (ACh) and neuropeptides is still greatly under speculation.

We began our histochemical investigation on the interation between cholinergic and peptidergic mechanisms by means of a colocalization of acetylcholinesterase (AChE) activity and immunoreactivity of some neuropeptides (1). However, AChE histochemistry could not provide definitive arguments on the cholinergic nature of neurons.

Concurrently with AChE histochemistry, we investigated a direct cytochemical method for the localization of ACh-like cation in the synaptic vesicles of the cholinergic nerve terminals (12). The method consists of precipitating vesicular ACh by means of silicotungstic acid or its analogous compounds (ionic fixation of ACh) (13). A relatively high specificity for such ACh precipitation was confirmed by an in vitro study (10) and by a comparative cytochemical study on cholinergic and non cholinergic nerve terminals (14).

In order to perform a cytochemical investigation of both cholinergic and pep-

\footnotetext{
${ }^{+}$: To whom correspondence should be sent.
} 
tidergic mechanisms at ultrastructural level, it seemed to us useful to combine the ionic fixation of ACh-like cation with an immunocytochemical localization of neuropeptides. Indeed, as an ultrastructural marker of cholinergic nerve terminals, the ionic fixation of ACh-like cation may be useful since immunocytochemistry of choline acetyltransferase in the peripheral nervous system (5) and that of $\mathrm{ACh}$ in general $(6,3)$ is still available only at light microscopic level. Concerning ultrastructural localization of neuropeptides in the myenteric plexus, few detailed studies were done $(8,9)$. In the present work, in order to preserve tissual ACh, neither Triton X100 treatment nor freezing and thawing of the tissues was performed before peptide immunocytochemistry. Immunocytochemical reaction was immediately followed by ionic fixation of ACh-like cation. Our preliminary results indicated that in the rat myenteric plexus both substance $P$ and vasoactive intestinal polypeptide (VIP) nerve endings were identified to a part of cholinergic nerve terminals.

\section{MATERIALS AND METHODS}

Male Wistar rats were killed by exsanguination under ether anaesthesia. Segments of ileum were removed and fixed for at least $24 \mathrm{hr}$ in $4 \%$ paraformaldehyde in $0.1 \mathrm{M}$ phosphate buffer $\mathrm{pH} 7.2$. The longitudinal muscle layer containing myenteric plexus was carefully separated from the circular muscle and the submucous layer.

The longitudinal muscle layer was subjected to an immunocytochemical procedure adaptated from the peroxidase-antiperoxidase method (11). After a wash in phosphate buffer saline (PBS), the tissues were successively immersed in normal goat serum (dilution $1: 20$ ) for $1 \mathrm{hr}$ (to avoid non specific binding of antibodies) and in the specific rabbit antisera raised against either substance P (dilution 1:1000, R-2042 Yanaihara) or VIP (dilution 1: 1000, R-502 Yanaihara) for $24 \mathrm{hr}$ at $4^{\circ} \mathrm{C}$ (previous treatment by Triton X-100 was avoided in order to preserve ACh-like cation in the cholinergic synaptic vesicles). Tissues were then treated with goat secondary anti rabbit antibodies for $2 \mathrm{hr}$ (dilution 1:50 in PBS) and with rabbit peroxidase-antiperoxidase complex for $2 \mathrm{hr}$ (dilution $1: 100$ in PBS). Tissues were washed in PBS between each incubation with immunoserum. The peroxidase activity of the immuno-complex was revealed with a method modified from Graham and Karnovsky (7): 3-5 mg of diaminobenzidine tetrahydrochloride (DAB) was dissolved in $10 \mathrm{ml}$ of $\mathrm{PBS}$ in which the tissues were immersed. After $10 \mathrm{~min}, \mathrm{H}_{2} \mathrm{O}_{2}$ was added to the DAB solution to a final concentration of $0.01 \%(w / v)$. Because of incompatibility with ionic fixation no ammonium nickel sulfate was used for increasing the intensity of $\mathrm{DAB}$ reaction. Some pieces of tissue were washed in PBS, and mounted on covered slides in aquamount medium for observation at light microscopic level.

After washing in PBS, tissues were treated successively by a $5 \%$ aqueous solution of silicotungstic acid for $30 \mathrm{~min}$ and by a mixture of $2.5 \%$ silicotungstic acid and $2 \%$ $\mathrm{OsO}_{4}$ for $30 \mathrm{~min}$. After washing in water and dehydration in a graded series of alcohol solutions, tissues were embedded in Epon. Ultrathin sections were observed without counterstaining under a JEOL $200 \mathrm{CX}$ electron microscope at $80 \mathrm{KV}$.

Controls for the immunocytochemical reaction were made by replacing specific neuropeptides antibodies by normal rabbit antiserum or by preincubating the specific anti-substance $P$ or anti-VIP antiserum with $10^{-5} \mathrm{M}$ substance $\mathrm{P}$ or $10^{-5} \mathrm{M}$ VIP, 


\section{respectively.}

In order to evaluate to what extent the immunocytochemical reaction was affected by the absence of any membrane permeabilization, some pieces were treated by $1 \%$ Triton $\mathrm{X}-100$ during the $2 \mathrm{hr}$ before immunocytochemical procedure.

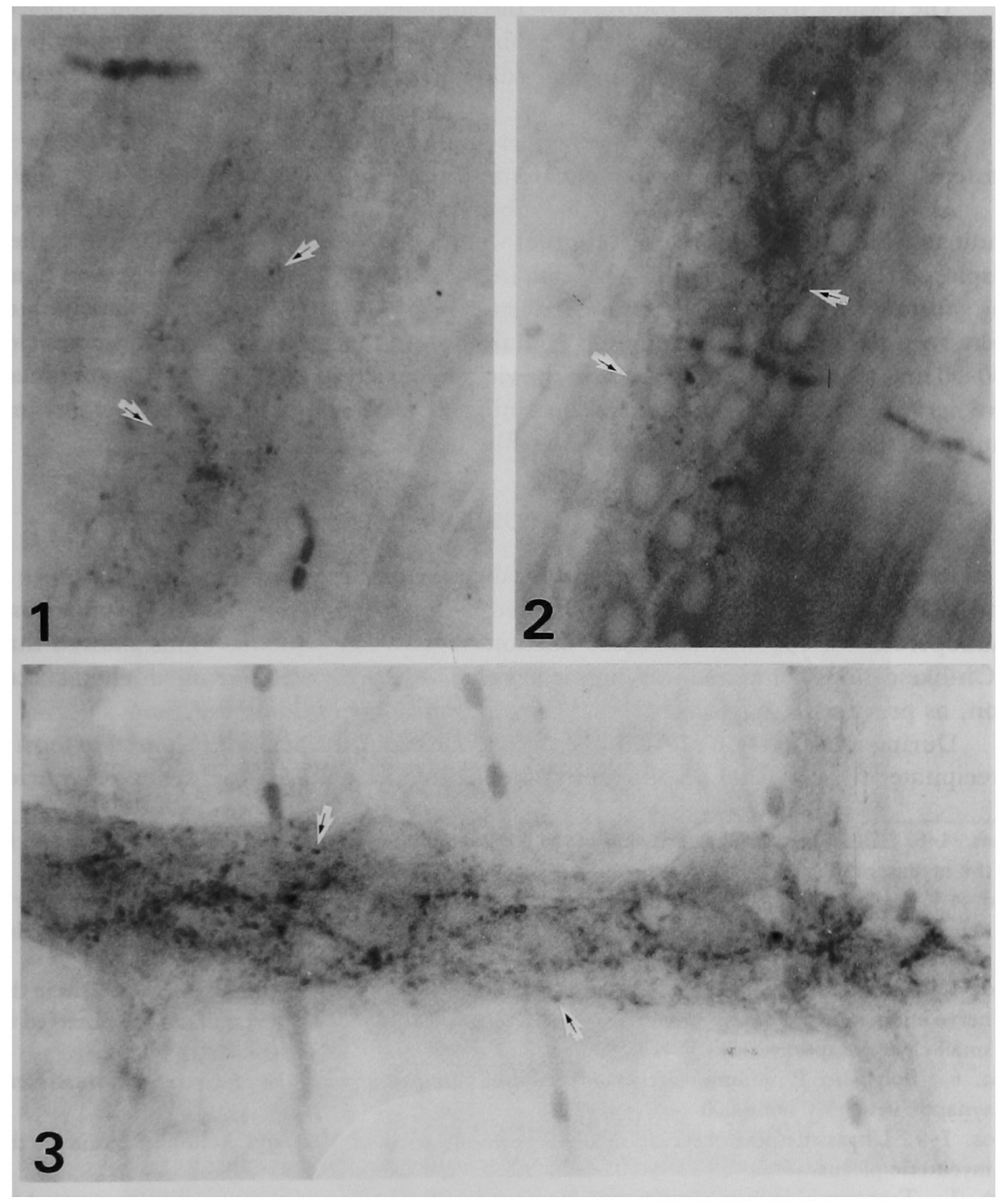

FIGs. 1-3. Light microscopy.

Figs. 1, 2. Myenteric plexus treated for colocalization of neuropeptides and ACh-like cation without any membrane permeabilization. Neuropeptides immunoreactive nerve endings are seen at dots (arrows) in the vicinity of the neuron cell bodies. Fig. 1. Substance P. Fig. 2. VIP. $\times 400$

Fic. 3. With pretreatment by $1 \%$ Triton $X-100$. Immunoreactivity of nerve endings (arrows) is more intense than in Figs. 1 and 2. Substance P. $\times 500$ 


\section{RESULTS}

Despite the absence of any procedure for membrane permeabilization. The immunocytochemical reaction, though less intense than that after treatment by Triton $\mathrm{X}-100$, could take place as it was observed at light microscopic level (Figs. 1-3).

The tissues treated as controls for the immunocytochemical reaction (replacement of specific antibodies by normal rabbit serum or preincubation of specific peptides antisera with corresponding peptide) did not display any specific immunoreactivity.

The localization of the neuropeptides immunoreactivity was not affected by a posterior silicotungstic acid treatment (ionic fixation of ACh-like cation) (Figs. 4-9).

At electron microscopic level, the substance P-and VIP-immunoreactive nerve endings were identified thanks to the well-known dark $D A B$ precipitates they displayed (Figs. 4-9). Point-like precipitates of ACh-like cations were observed in all the substance P- and VIP-immunoreactive nerve endings studied. These precipitates were seen only in the nerve endings containing a lot of small clear synaptic vesicles (30-50 nm) (Figs. 6-9). Moreover, in the vicinity of substance P- or VIP-immunoreactive nerve terminals, nerve endings containing ACh-like cations but devoid of any immunoreactivity were seen (Figs. $4,5,7,8$ ).

\section{DISCUSSION}

In the present work, simultaneous localization of some neuropeptides (subtance $P$ and VIP) and ACh-like cation was obtained by the combination of neuropeptides immunoperoxidase reaction and ionic fixation of ACh-like cations. This showed that ACh-like cations contained in synaptic vesicles were preserved during aldehydic fixation, as previously suggested (2) and during immunoperoxidase reaction.

During ionic fixation of ACh-like cation, silicotungstic acid is presumed to form a precipitate of acetylcholine silicotungstate (insoluble salt) in the synaptic vesicles

Figs. 4-6. Ultrastructural observation of the colocalization of substance $\mathrm{P}$ and ACh-like cation in the myenteric plexus.

FIG. 4. Several subtance P-immunoreactive nerve terminals (arrow) are seen containing or near a neuronal cell body (N). a nerve terminal devoid of any immunoreactivity (arrowhead) is also observed contacting the same neuronal cell body. $\times 13,000$

FIG. 5. Detail of Fig. 4. In the nerve ending displaying immunoreactivity (arrow) as well as in the nerve ending devoid of any immunoreactivity (arrowhead) point-like precipitates are observed in small clear synaptic vesicles. $\times 52,000$

FIG. 6. Substance $\mathrm{P}$-immunoreactive nerve ending displaying point-like precipitates in small clear synaptic vesicles. $\times 66,000$

FIGS. 7-9 Ultrastructural observation of the colocalization of VIP and ACh-like cation in the myenteric plexus.

FIG. 7. Transversal section of myenteric plexus. A VIP-immunoreactive nerve ending (arrow) (cf Fig. 9) and a non-immunoreactive nerve ending (arrowhead) (cf Fig. 8) are observed. LM: longitudinal muscle layer, $\mathrm{Np}$ : neuropile. $\quad \times 5,300$

FIG. 8. Detail of Fig. 7. Non immunoreactive nerve ending (arrowhead) displaying point-like precipitates in small clear synaptic vesicles. $\times 63,000$

FIG. 9. Detail of Fig. 7. VIP-immunoreactive nerve ending (arrow) displaying point-like precipitates in small clear synaptic vesicles. $\times 64,000$ 


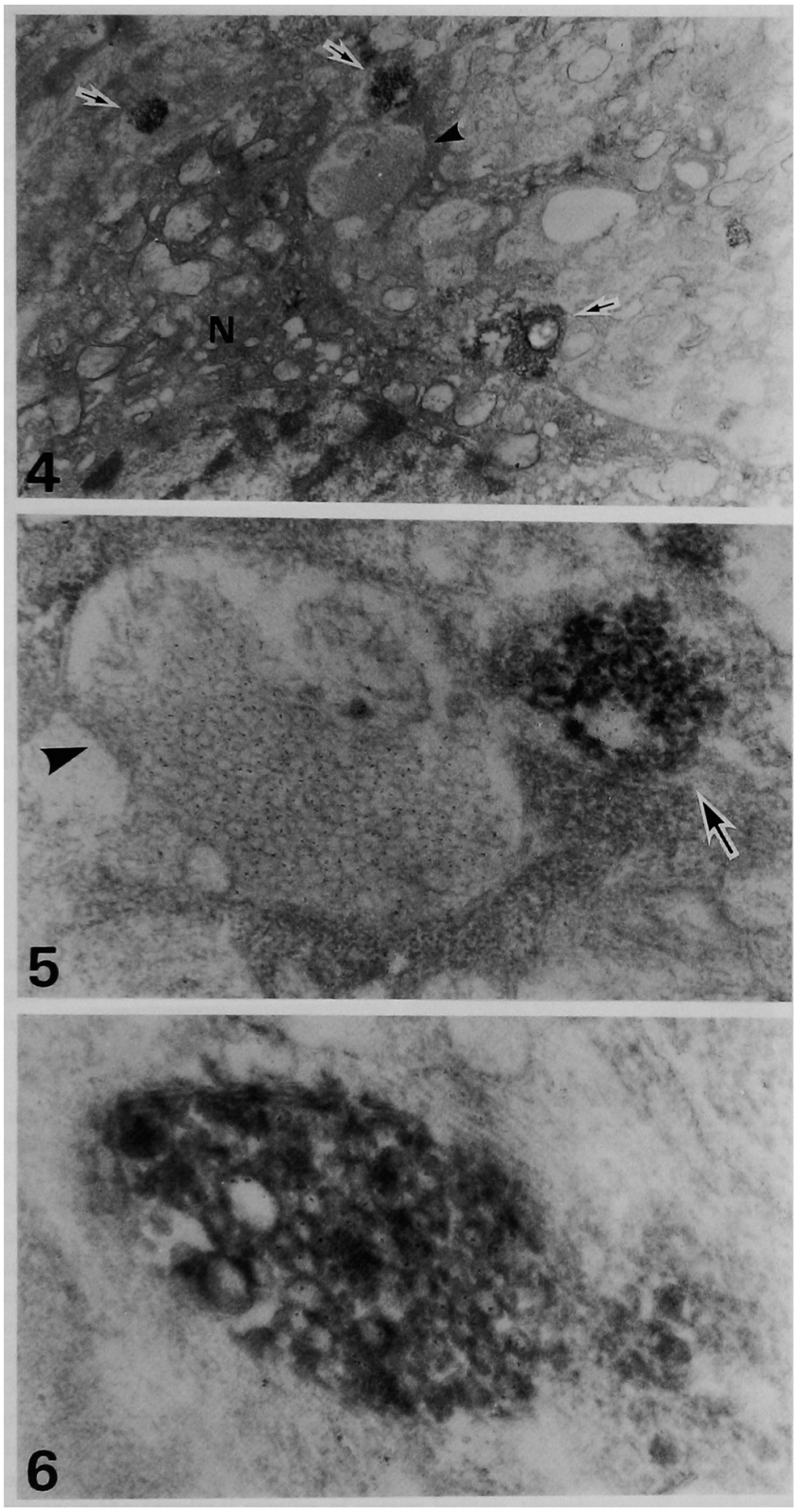



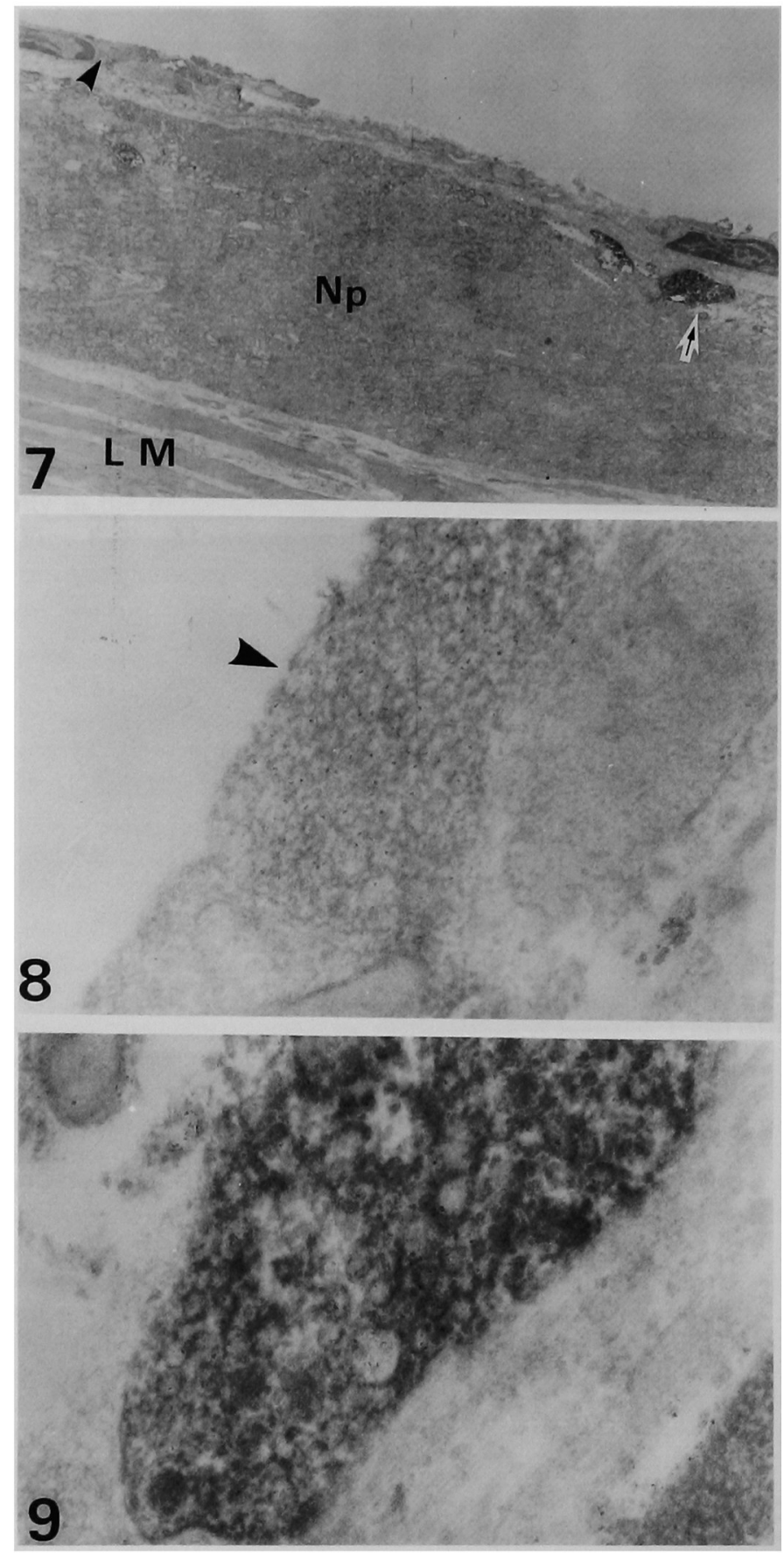
(13). In addition, it was found that silicotungstic acid also precipitated DAB, which is a quaternary ammonium compound. Thus, silicotungstic acid not only provided an ultrastructural localization of ACh-like cation in the synaptic vesicles but also stabilized the $\mathrm{DAB}$ precipitates, reducing their diffusion during the osmification of the tissues.

In the myenteric plexus, only a few detailed ultrastructural studies on neuropeptides were reported $(8,9)$. In the present study, the localization of peptidergic nerve terminals of two peptides (substance $P$ and VIP) was compared to the localization of ACh-like cation at ultrastructural level. Both substance $P$ and VIP nerve terminals were identified with one part of the nerve terminals containing ACh-like cation.

We could not conclude from this study whether, in the myenteric plexus, substance $\mathrm{P}$ and VIP were situated in the same nerve terminals also containing AChlike cation. However, colocalization of these peptides in the myenteric plexus at light microscopic level (4) and quantitative ultrastructural immunocytochemistry of the peptides in the circular muscle layer of the intestine (9) suggested that substance $P$ and VIP were situated in different nerve terminals. A triple colocalization of substance $P$, VIP and ACh-like cation is under investigation.

\section{ACKNOWLEDGMENTS}

We thank Prof. N. Yanaihara (Shizuoka Univ.) who kindly provided us the antisera and Prof. T. Ozaki (National Institute for Physiological Sciences, Okazaki) for his constant support during this work.

During this work Dr. P. Anglade was supported by a fellowship of the "Japan Society for the Promotion of Science".

\section{REFERENCES}

1. Anglade, P., Ozaki, T., Michel, C., Tsuji, S., Vignon, X. and Yanaihara, N.: Simultaneous localization of acetylcholinesterase activity and met-enkephalin, vasoactive intestinal peptide and substance $\mathrm{P}$ immunoreactivity in the rat myenteric plexus. Histochem. J. 20; 464-467, 1988.

2. Birks, R. I.: Effects of stimulation on synaptic vesicles in sympathetic ganglia as shown by fixation in the presence of $\mathrm{Mg}^{2+}$. J. Physiol. 216; 26-28, 1971.

3. Chagnaud, J. L., Souan, M. L., Charrier, M. C. and Geffard, M.: Monoclonal anti-conjugated acetylcholine antibody and immunocytochemical applications in rat nervous system. J. Neurochem. 53; 383-391, 1989.

4. Domoto, T., Gonda, T., Oki, M. and Yanaihara, N.: Coexistence of substance P- and methionine ${ }^{5}$-enkephaline-like immunoreactivity in nerve cells of the myenteric ganglia in the rat ileum. Neurosci. Lett. 47; 9-13, 1984.

5. Furness, J. B., Costa, M. and Keast, J. R.: Choline acetyltransferase and peptide immunoreactivity of submucous neurons in the small intestine of the guinea-pig. Cell Tiss. Res. 237; 329-336, 1984.

6. Geffard, M., Mc Rae-Degueurce, A. and Souan, M. L.: Immunocytochemical detection of acetylcholine in the rat central nervous system. Science 229; 77-79, 1985.

7. Graham, R. C. and Karnovsky, M. J.: The early stages of absorption of injected horseradish peroxidase in the proximal tubules of mouse kidney: ultrastructural cytochemistry by a new technique. J. Histochem. Cytochem. 14; 291-302, 1966. 
8. Llewellyn-Smith, I. J., Furness, J. B. and Costa, M.: Ultrastructural analysis of substance P immunoreactive nerve fibers in myenteric ganglia of guinea-pig small intestine. J. Neurosci. 9; 167-174, 1989.

9. Llewellyn-Smith, I. J., Furness, J. B., Gibbins, I. L. and Costa, M.:Quantitative ultrastructural analysis of enkephalin-, substance P-, and VIP-immunoreactive nerve fibers in the circular muscle of the guinea-pig small intestine. J. Comp. Neurol. 272; 139-148, 1988.

10. Ohoka, T. and Tsuji, S.: Specificity of ionic fixation with silicotungstic acid for cytochemical localization and identification of acetylcholine in synaptic vesicles. Biomed. Res.: 9; 335-341, 1988.

11. Sternberger, L. A., Hardy, P. H., Cuculis, J. J. and Meyer, M. G.: The unlabelled antibody enzyme method of immunocytochemistry. Preparation and properties of soluble antigen-antibody complex (horseradish peroxidase-anti-horseradish peroxidase) and its use in identification of spirochetes. J. Histochem. Cytochem. 18; 315-333, 1970.

12. Tsuji, S. and Alameddine, H. S.: Silicotungstic acid for cytochemical localization of water soluble substance(s) of cholinergic nerve terminal. Histochemistry 73; 33-37, 1981.

13. Tsuji, S., Alameddine, H.S., Nakanishi, S. and Ohoka, T.: Molybdic and tungstic heteropolyanion for "ionic fixation" of acetylcholine in cholinergic motor nerve terminals. Histochemistry 77; 51-56, 1983.

14. Tsuji, S. and Anglade, P.: Acetylcholine in neurons and paraneurons: A histochemical study. Arch. Histol. Cytol. 52; Suppl., 75-83, 1989. 